\title{
Old World, new development
}

\author{
Wolfgang Stoiber
}

\author{
Biotechnology and Competitive \\ Advantage: Europe's Firms and the \\ US Challenge
}

Edited by Jacqueline Senker

1998 Edwand Elgar Publishing, 192 pages, $\$ 70$ hardcover

Europe's engagement in and commitment to biotechnology has been the subject of significant controversy over the past 10 years. Powerful antitechnology forces have applied their influence to block biotechnology's growth in Europe, but technology seems to be the only solution to effect the change necessary to create the high valueadded employment opportunities industrialized countries need to contain unemployment.

In 1994, the European Commission (EC) decided to fund a number of studies to assess the situation European biotechnology was faced with and to draw comparisons to the development of this sector in the US. The objective was to guide policy for the EC affecting the European Union and its member states. Biotechnology and Competitive Advantage makes the results of these studies public and contributes to the academic understanding of the driving innovation and the policy measures that channel these forces.

As the research for the chapters was done between 1994 and 1996, the results presented do not necessarily reflect an accurate description of today's biotech landscape in Europe. The impact of some developments, such as BioRegio in Germany or the disillusionment with biotech we see in the US and the UK, are therefore not reflected. Some other elements, such as the lack of venture capital in Europe, have been largely resolved in the meantime. Still, the book serves two purposes: First, it provides a review of the situation in European biotech before 1996, and has value in describing the basis for EC policy decisions. Second, it spells out some interesting reflections on the general issues of the industry, such as business models, the

Wolfgang Stoiber is managing director of MPM Capital Advisors, One Cambridge Center, Cambridge, MA 02142 (wstoiber@mpmcapital.com). dynamics of strategic alliances, and value chain/integration questions.

One of the book's highlights is Saviotti's analysis of the structure of the biotechnology industry and his examination of the factors determining entry into biotechnology. Among more traditional factors such as availability of capital or profit expectation, he describes the dynamics of knowledge creation as a key determinant favoring the entry of new players who do not necessarily replace incumbents, but rather play new roles in a universe of knowledge discontinuity, such as intermediaries between large

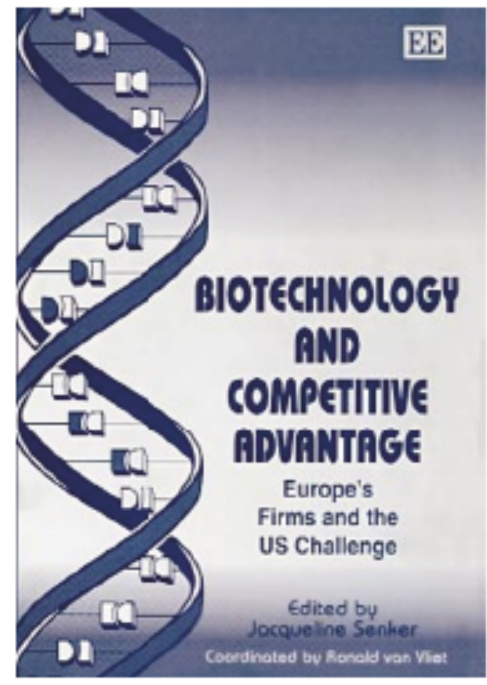

corporations and academia. He is, however, quite concerned about the first-mover advantages the early entrants enjoy, that is, being able to lock up entire areas of technology, a concern echoed in the chapter by Acharya, Arundel, and Orsenigo.

Translated into policy recommendations, Acharya et al. worry about the ability of European startups to catch up or be behind forever. This concern is a real one, and we have seen a number of new companies formed in Europe finding themselves in situations where they have struggled against dominating intellectual property positions or locked-up markets. On the other hand, it seems that the knowledge discontinuities generated by the rapid progression of science in biotech level the playing field enough so that the excellence in science we find in Europe can bring new entrants to the forefront of their respective market segment.

The authors examine the role of multinational pharmaceutical corporations and their role in the creation of networks of partners. The current trend toward outsourcing some pharmaceutical research activities is recognized, and the question is raised: ${ }^{\alpha}$ Will this trend be sustainable?" So long as the high speed of innovation continues, there is little doubt it will; as the industry matures, there are forces driving it toward a more hierarchical structure. The more developed biotech companies take on the role of system integrators, a role that has traditionally been the domain of large pharmaceutical corporations, but is increasingly being shared with the larger biotech companies.

The authors also describe a particular European way of direct interaction between academic researchers and multinational pharmaceutical corporations. One is left to wonder if that European way of "buying direct $^{\infty}$ is generating a sufficient flow of innovation and if it is sustainable, given the limited incentives for the creative forces in the process. Looking at the recent explosion of new biotech startups in Europe, it seems that the knowledge creators in universities have begun to realize that they can maximize value by putting their expertise to work in small startups.

Agricultural biotechnology is the focus of Chataway and Assouline's chapter, ${ }^{\alpha}$ Risk Perception, Regulation and Management." Purely technocratic assessment of risk is not convincing, as it can be turned around very easily by antitechnology groups demanding a zero-risk strategy. The authors underline the importance of societal consensus, which can be influenced by communication and information. To the reader in the biotech industry, it may be striking that the chapter only deals with risk and not with the benefits associated with biotechnology.

Biotechnology and Competitive Advantage will appeal to, as the publisher puts it, "science policy makers, businesses and academics studying the development of biotechnology, and students of economics and business studies throughout Europe and the US." This is accurate, as long as leaders realize the factual basis of the studies discussed here has been altered by very dynamic developments in some parts of Europe. 